\title{
Desenvolvimento vegetativo e associação micorrízica em plantas de mandioca adubadas com resíduo agroindustrial ${ }^{1}$
}

\section{Development of cassava plants and its mycorrhizal association in soil supplemented with sugarcane agroindustrial residue ${ }^{1}$}

\author{
Jorge Messias Leal do Nascimento ${ }^{2}$; Maylane Rayane Brito dos Santos ${ }^{3}$; \\ Mario Adriano Ávila Queiroz ${ }^{4}$; Adriana Mayumi Yano-Melo ${ }^{5 *}$
}

\begin{abstract}
Resumo
A aplicação de resíduos orgânicos oriundo da agroindústria na agricultura pode ser uma alternativa para incrementar o crescimento e composição químico-bromatológica das plantas, reduzindo os custos com fertilizantes químicos e os impactos que podem ser gerados pelo uso excessivo destes. O resíduo agroindustrial de cana-de-açúcar é gerado em grandes quantidades na região semiárida brasileira, podendo ser aplicado à cultura da mandioca a fim de melhorar seu crescimento. Nesse sentido, o presente trabalho teve por objetivo avaliar o efeito da aplicação de resíduo agroindustrial no desenvolvimento vegetativo, características químico-bromatológica e associação micorrízica de plantas de mandioca (Manihot esculenta variedade 'Engana ladrão'). Foi realizado um experimento em casa de vegetação em delineamento inteiramente casualizado, com quatro tratamentos $(0,5,10$ e $15 \%)$ de adição de resíduo de bagaço de cana-de-açúcar enriquecido com torta de filtro, em nove repetições. A adição de resíduo de cana-de-açúcar enriquecido promoveu aumento na biomassa fresca e seca radicular, área foliar, proteína bruta e matéria mineral, além de não afetar negativamente a colonização micorrízica e o número de glomerosporos. Este tipo de resíduo pode ser uma alternativa para melhorar o valor nutritivo da forragem.
\end{abstract}

Palavras-chave: Bagaço de cana, bromatologia, forragem, Manihot esculenta, matéria orgânica, micorriza

\begin{abstract}
Application of organic agroindustrial residues on agriculture can be one way to improve the development and chemical composition of plants, reducing the cost with chemical fertilizers and impacts generated by the excessive use of them. Sugarcane agroindustrial residue has been generated in high quantity in Brazilian semiarid region and can be applied to cassava crop to improve its growth. The aim of this work was to evaluate the effect of application of sugarcane agroindustrial residue on the vegetative development, chemical composition and mycorrhizal association of cassava plants (Manihot esculenta var. Engana ladrão). It was performed an experiment in greenhouse with completely randomized design

\footnotetext{
${ }_{1}^{1}$ Parte da Dissertação de Mestrado do primeiro autor em Ciência Animal, Universidade Federal do Vale do São Francisco, Univasf, Petrolina, PE.

2 Zootecnista, M.e em Ciência Animal, discente do Curso de Doutorado do Programa de Pós-Graduação em Ciências Agrárias, área de Fitotecnia, Universidade Federal do Recôncavo da Bahia, UFRB, Cruz das Almas, BA. E-mail: jorge_messias@ymail. com

3 Discente do Curso de Graduação em Zootecnia/UNIVASF, Petrolina, PE. E-mail: may 15 lane@hotmail.com

${ }^{4}$ Zootecnista, Dr. em Ciência Animal e Pastagem e Prof. do Colegiado de Zootecnia, CZ̄OO, Campus de Ciências Agrárias, Univasf, Petrolina, PE. E-mail: mario.queiroz@univasf.edu.br

${ }_{5}^{5}$ Bióloga, Dra em Ciências Biológicas e Prof. do Colegiado de Zootecnia, CZOO, Campus de Ciências Agrárias, Univasf, Petrolina, PE. E-mail: adriana.melo@univasf.edu.br

* Autor para correspondência
} 
with four treatments of addition of sugarcane agroindustrial residue $(0,5,10$ and $15 \%)$ with nine replicates. The addition of sugarcane agroindustrial residue increased fresh dry root biomass, leaf area, crude protein and mineral matter, without reducing the mycorrhizal colonization and glomerospores number. This type of residue can be one alternative to improve the nutritional value of these fodder.

Key words: Sugarcane agroindustrial residue, chemical composition, fodder, Manihot esculenta, organic matter, mycorrhizae

\section{Introdução}

A mandioca (Manihot esculenta Crantz.) planta da família Euphorbiaceae, é utilizada na alimentação humana e animal (BURGOS et al., 2010), devido à composição químico-bromatológica, que apresenta $26,2 \%$ de proteína bruta, 37,9 \% de fibra em detergente neutro e $43 \%$ de digestibilidade in vitro da matéria seca da parte aérea (FERREIRA et al., 2009). Além disso, esta espécie pode ser cultivada em solos ácidos e com baixa fertilidade natural (NASSAR; ORTIZ, 2006). Ressalta-se ainda que, plantas de mandioca apresentam resistência a períodos de estiagem e capacidade de utilização eficiente da água do solo, o que possibilita o seu cultivo em regiões de secas prolongadas (SILVA et al., 2009).

O sistema radicular da mandioca é composto por raízes grossas e pouco abundantes, com poucos pelos absorventes, resultando em menor superfície específica disponível para absorção de água e nutrientes do solo (COLOZZI-FILHO; NOGUEIRA, 2007). Tais características podem explicar a importância da associação com fungos micorrízicos arbusculares (FMA) em plantas do gênero Manihot, visto que esses fungos podem auxiliar o estabelecimento e manutenção das plantas no campo, devido à melhoria na nutrição mineral, principalmente em solos considerados pouco férteis (BALOTA et al., 1997).

Os FMA realizam simbiose mutualística obrigatória com a maioria das espécies vegetais, expandindo a área de atuação das raízes e potencializando o seu desenvolvimento com incrementos na absorção de nutrientes e água do solo, melhorando assim o estado fisiológico das plantas (SMITH; READ, 2008). Segundo Omorusi e Ayanru (2011), plantas de mandioca apresentam capacidade de extrair grandes quantidades de nutrientes em solos com baixa fertilidade natural, desde que associadas a FMA.

Além da associação com FMA, as plantas de mandioca podem aumentar o desenvolvimento a partir da adubação com matéria orgânica, logo este melhora os atributos químicos, físicos e biológicos do solo. Resíduos vegetais para melhoria das propriedades do solo têm sido utilizados em plantas de mandioca, Amabile et al. (1994) observaram incremento na produção de biomassa radicular com adição de adubo verde provindo de plantas de Crotalaria juncea L. Similarmente, Otsubo et al. (2008) obtiveram aumentos na produção de biomassa seca aérea em plantas de mandioca cultivadas com adição de resíduos de Pennisetum glaucum L. R. Br.

Outras fontes de matéria orgânica (MO) foram testadas visando melhorias no desenvolvimento de plantas de mandioca, dentre estas, a adição de esterco bovino, que proporcionou maior biomassa seca aérea (BELTRÃO et al., 2008) e maior número de folhas (FERREIRA et al., 2010). Vasconcelos et al. (2010) acrescentam ainda que a adubação com esterco bovino incrementou a biomassa fresca e seca aérea, altura e diâmetro do caule, além de ter proporcionado maior acúmulo de minerais e proteína bruta na parte aérea de plantas de mandioca. Em sistema orgânico de produção de mandioca, Devide et al. (2009) observaram aumento na produção de biomassa fresca aérea e radicular.

Okon et al. (2010) demonstraram aumento na colonização micorrízica em raízes de plantas de mandioca colonizadas por Glomus deserticola Trappe, Bloss \& J.A. Menge com o uso de 
cobertura morta. De forma similar, Schiavo et al. (2010) verificaram aumento no percentual de colonização micorrízica em plantas de Jatropha curcas L. micorrizadas por G. clarum T.H. Nicol. \& N.C. Schenck e adubadas com composto orgânico (Organosuper®). Entretanto, o tipo e a dose de MO aplicada ao solo podem resultar em efeitos distintos sobre a colonização micorrízica e quantidade de propágulos de FMA. Recentemente, Nakatani et al. (2011) constataram redução na densidade de glomerosporos e diversidade de FMA em solos cultivados com Zea mays L. e adubados com lodo de curtume.

No Brasil, a cultura da cana-de-açúcar ocupa área de aproximadamente 9.947,380 ha sendo a produção máxima de 651 . 629,170 ton e o estado da Bahia apresenta produção média de 6.542,843 ton/ha, ocupando o terceiro lugar em relação aos demais estados da região Nordeste. A atividade sucroalcooleira gera quantidade significativa de resíduos que podem ser utilizados como fontes de nutrientes para as plantas, melhorando a produtividade vegetal. Assim, Miranda, Rigone e Silveira (2011) constataram que a adubação orgânica com torta de filtro de cana de açúcar aumentou o diâmetro do colmo, altura e número de perfilhos em plantas de Saccharum officinarum L., demonstrando o potencial de uso deste resíduo em incrementar a produção agrícola. Por outro lado, Calgaro et al. (2008), mencionam que a adição de bagaço de cana-de-açúcar na rizosfera de plantas de Stryphnodendron polyphyllum Mart. promoveu aumento nos percentuais de colonização micorrízica por FMA autóctone.
Embora se conheça os benefícios da adubação com resíduos da agroindústria da cana-de-açúcar em incrementar o desenvolvimento vegetativo e associação micorrízica em algumas espécies vegetais, não há estudos sobre os efeitos, as doses a serem recomendadas e o possível impacto deste resíduo na associação micorrízica em rizosfera de plantas de mandioca. Desta forma, o objetivo deste trabalho foi avaliar o efeito da aplicação do resíduo agroindustrial composto de bagaço de cana-de-açúcar enriquecido com torta de filtro, no desenvolvimento inicial, na composição químicobromatológica e associação micorrízica de plantas de mandioca variedade 'Engana ladrão'.

\section{Material e Métodos}

Foi realizado experimento em casa de vegetação, adotando-se delineamento inteiramente casualizado com quatro doses de resíduo de bagaço de cana-deaçúcar enriquecido com torta de filtro (Agrovale) (T1 - 0\%, T2 - 5\%, T3-10\%, T4-15\%), em nove repetições. Utilizou-se o Neossolo Quartzarênico, coletado até a profundidade de $0-20 \mathrm{~cm}$, seco ao ar, destorroado, homogeneizado, tamisado em peneiras com malhas de 2,0 $\mathrm{mm}$ e analisado quimicamente (Tabela 1). Como fonte de matéria orgânica, foi utilizado resíduo agroindustrial oriundo da atividade sucroalcooleira, bagaço de cana-de-açúcar enriquecido com torta de filtro - BCE, fornecido pela empresa Agrovale (Juazeiro - BA), o qual foi analisado quimicamente (Tabela 1). 
Tabela 1. Caracterização química do Neossolo quartzarênico (NEO) e do bagaço de cana-de-açúcar enriquecida com torta de filtro (BCE) utilizada em experimento com plantas de mandioca variedade 'Engana ladrão' em casa de vegetação.

\begin{tabular}{|c|c|c|c|c|c|c|c|c|c|c|}
\hline \multirow[t]{2}{*}{ SUBSTRATOS } & \multirow{2}{*}{$\begin{array}{l}\text { M.O. } \\
\text { g/kg }\end{array}$} & \multirow[t]{2}{*}{$\mathrm{pH}^{*}$} & \multirow{2}{*}{$\begin{array}{l}\text { C.E. } \\
\text { dS/m }\end{array}$} & \multirow{2}{*}{$\begin{array}{c}P \\
\mathrm{mg} / \mathrm{dm}^{3}\end{array}$} & CTC & $\mathbf{K}$ & $\mathrm{Ca}$ & Mg & $\mathrm{Na}$ & Al \\
\hline & & & & & \multicolumn{6}{|c|}{$\mathrm{cmol} / \mathrm{dm}^{3}$} \\
\hline NEO & 11,40 & 6,40 & 0,66 & 21,38 & 9,30 & 0,51 & 3,40 & 2,20 & 0,06 & 0,05 \\
\hline BCE & 61,00 & 8,00 & 1,86 & $1.477,50$ & 18,20 & 1,06 & 12,60 & 2,50 & 0,37 & 0,00 \\
\hline
\end{tabular}

M.O.= matéria orgânica; C.E. $=$ condutividade elétrica; $\mathrm{pH}^{*}=\mathrm{H}_{2} \mathrm{O}-1: 2: 5 ;$ CTC- capacidade de troca catiônica; $\mathrm{NEO}=$ Neossolo quartzarênico; BCE= Bagaço de cana-de-açúcar enriquecido.

Fonte: Elaboração dos autores.

As mudas de mandioca variedade Engana ladrão (TSA-1/BGM1269) foram obtidas a partir de manivas com 6 a $8 \mathrm{~cm}$ de comprimento, que permaneceram por aproximadamente 30 dias em bandejas, com areia autoclavada para o enraizamento, sendo posteriormente transplantas (uma planta/vaso) para vasos com capacidade de $3000 \mathrm{ml}$ de solo nos respectivos tratamentos de adubação orgânica.

O experimento foi conduzido por 90 dias (idade das plantas ao término do estudo), sendo as plantas irrigadas diariamente. Ao final desse período foi avaliada a altura - ALT (medida da distância entre o nível do solo e a inserção do broto terminal da haste principal), número de folhas - NF, diâmetro do ramo - DR (medido a cinco centímetros da base do solo). Para aferição do DR das plantas de mandioca utilizou-se um paquímetro digital $(\mathrm{mm})$ e para a ALT foi utilizado uma trena com extensão em centímetros. Foram avaliados também a área foliarAF com auxílio do programa computacional Quant. (VALE; FERNANDES FILHO; LIBERATO, 2003), as biomassas frescas aérea e radicular - BFA e BFR e, em seguida procedeu-se a secagem do material em estufa de circulação de ar forçada a $65{ }^{\circ} \mathrm{C}$ por 72 horas para posterior determinação das biomassas seca aérea e radicular - BSA e BSR (SILVA; QUEIROZ, 2002). A partir da secagem da BFA, realizou-se a caracterização químico-bromatológica das amostras vegetais, em termos de matéria seca (MS), matéria mineral (MM), MO, proteína bruta (PB), fibra em detergente neutro e ácido (FDN e
FDA), segundo as metodologias descritas por Silva e Queiroz (2002).

Foi avaliado o número de glomerosporos no solo (NG) (GERDEMANN; NICOLSON, 1963; JENKINS, 1964) e a colonização micorrízica (CM) pela técnica de interseção dos quadrantes (GIOVANETTI; MOSSE, 1980), após a diafanização e coloração das raízes (PHILLIPS; HAYMAN, 1970). Após a avaliação das variáveis, os dados de colonização micorrízica foram transformados em raiz quadrada de $\mathrm{x} / 100$ e os de número de glomerosporos em $\log$ de $x+1$, em seguida foram analisados juntamente com os demais variáveis pelo procedimento GLM. As médias de cada tratamento foram obtidas pelo comando LSMEANS. Diferenças significativas foram consideradas a 5\% de probabilidade $(\mathrm{p} \leq 0,05)$. Para as variáveis que obtiveram respostas significativas utilizou-se o teste para polinômios ortogonais lineares e quadráticos do programa estatístico SAS (2003).

\section{Resultados e Discussão}

Houve efeito significativo da adição das doses de bagaço de cana-de-açúcar enriquecido com torta de filtro para BFA, BSA, AF, ALT, DR, MO, PB e MM de plantas de mandioca variedade 'Engana ladrão' (Tabela 2 e 3). Em geral, o maior incremento nos variáveis vegetativos foi obtido com a adição de até $10 \%$ de bagaço de cana-de-açúcar enriquecido, exceto para a $\mathrm{AF}$ e MM, nos quais maiores médias foram observadas com $15 \%$ de adição do resíduo 
orgânico, sendo observado para MM linearidade crescente, enquanto que a AF apresentou comportamento quadrático (Tabelas 2 e 3). Beltrão et al. (2008) obtiveram incremento de 54,4 \% na BSA de plantas de Manihot pseudoglaziovii Muell. Arg. com a aplicação de $1,8 \mathrm{~kg} / \mathrm{ha}$ de esterco bovino em relação ao tratamento controle. Da mesma forma, Ferreira et al. (2010) e Vasconcelos et al. (2010) verificaram aumento na produção de biomassa fresca e seca de plantas de M. pseudoglaziovii e Manihot sp. (pornuncia) com a adição de esterco e resíduo oriundo da digestão de bovinos ao substrato de cultivo. Outras fontes de matéria orgânica parecem promissoras para a produção de biomassa de mandioca, como resíduo de P. glaucum (OTSUBO et al., 2008), reforçando os benefícios do cultivo de plantas de mandioca em sistema orgânico, como sugerido por Devide et al. (2009).

Tabela 2. Variáveis de crescimento e micorrízicos em plantas de mandioca variedade 'Engana ladrão' cultivado com diferentes tratamentos $(0,5,10$, e $15 \%)$ de adubação com bagaço de cana-de-açúcar enriquecida com torta de filtro, após 90 dias de cultivo em casa de vegetação.

\begin{tabular}{|c|c|c|c|c|c|c|c|c|c|}
\hline \multirow{2}{*}{ VARIÁVEIS } & \multicolumn{4}{|c|}{ Bagaço de cana-de-açúcar (\%) } & \multicolumn{5}{|c|}{$\begin{array}{c}\mathbf{P}^{1} \\
\text { REGRESSÃo }\end{array}$} \\
\hline & $\mathbf{0}$ & 5 & 10 & 15 & $\mathbf{L}$ & $\mathbf{Q}$ & & $\mathrm{CV}$ & $\mathbf{R}^{2}$ \\
\hline BFA (g) & 20,59 & 20,30 & 19,75 & 11,51 & 'ns & * & $Y=-0,12 X^{2}+1,30 X+18,90$ & 18,26 & 0,72 \\
\hline BSA (g) & 5,45 & 5,64 & 6,04 & 2,74 & $\mathrm{~ns}$ & $*$ & $Y=-0,04 X^{2}+0,59 X+4,69$ & 18,38 & 0,76 \\
\hline BFR (g) & 10,57 & 10,67 & 14,99 & 11,98 & ns & ns & $\mathrm{Y}=12,05$ & - & - \\
\hline BSR (g) & 2,32 & 2,58 & 3,71 & 2,54 & ns & ns & $\mathrm{Y}=2,78$ & - & - \\
\hline $\mathrm{AF}\left(\mathrm{cm}^{3}\right)$ & 67,34 & 53,16 & 124,40 & 151,50 & $\mathrm{~ns}$ & $*$ & $Y=2,35 X^{2}-23,69 X+89,49$ & 34,81 & 0,84 \\
\hline ALT (cm) & 46,61 & 45,11 & 44,05 & 29,55 & ns & $*$ & $Y=-0,13 X^{2}+0,90 X+45,91$ & 14,13 & 0,58 \\
\hline DR (mm) & 6,55 & 6,32 & 5,86 & 5,07 & $*$ & ns & $\mathrm{Y}=-0,10 \mathrm{X}+6,75$ & 10,37 & 0,48 \\
\hline NF & 13,33 & 13,55 & 15,55 & 13,00 & ns & ns & $\mathrm{Y}=13,85$ & - & - \\
\hline CM $(\%)$ & 81,66 & 84,44 & 84,77 & 78,00 & ns & ns & $\mathrm{Y}=82,21$ & - & - \\
\hline NG ( $g^{-1}$ de solo) & 0,37 & 0,66 & 0,71 & 0,73 & ns & ns & $\mathrm{Y}=0,61$ & - & - \\
\hline
\end{tabular}

Biomassa fresca e seca aérea (BFA e BSA) e radicular (BFR e BSR), área foliar (AF), altura (ALT), diâmetro do ramo (DR), número de folhas $(\mathrm{NF})$, colonização micorrízica $(\mathrm{CM})$ e número de glomerosporos $(\mathrm{NG}) .{ }^{1}$ Valor de $P$ para o teste de polinômio ortogonal, resposta linear $(\mathrm{L})$ ou quadrática $(\mathrm{Q}) . *(\mathrm{P}<0,05)$.

Fonte: Elaboração dos autores.

Tabela 3. Variáveis químico-bromatológica de plantas de mandioca variedade 'Engana ladrão' cultivado com diferentes tratamentos $(0,5,10$ e $15 \%)$ de adubação com bagaço de cana-de-açúcar enriquecida com torta de filtro, após 90 dias em casa de vegetação.

\begin{tabular}{|c|c|c|c|c|c|c|c|c|c|}
\hline \multirow{2}{*}{$\begin{array}{c}\text { VARIÁVEIS } \\
(\%)\end{array}$} & \multicolumn{4}{|c|}{$\begin{array}{c}\text { Bagaço de cana-de-açúcar } \\
(\%)\end{array}$} & \multicolumn{2}{|c|}{$\mathbf{P}^{1}$} & \multirow[t]{2}{*}{ REGRESSÃO } & \multirow[t]{2}{*}{ CV } & \multirow[t]{2}{*}{$\mathbf{R}^{2}$} \\
\hline & $\mathbf{0}$ & 5 & 10 & 15 & $\mathbf{L}$ & $\mathbf{Q}$ & & & \\
\hline MS & 23,85 & 26,14 & 28,63 & 20,83 & ns & ns & $\mathrm{Y}=24,86$ & - & - \\
\hline МM & 7,73 & 9,35 & 10,58 & 11,28 & $*$ & ns & $\mathrm{Y}=7,66+0,26 \mathrm{X}$ & 10,10 & 0,71 \\
\hline MO & 92,27 & 90,75 & 89,12 & 88,72 & ns & $*$ & $Y=0,01 x^{2}-0,42 x+92,44$ & 0,46 & 0,93 \\
\hline PB & 11,97 & 12,77 & 16,86 & 13,99 & ns & $*$ & $Y=-0,03 x^{2}+0,74 x+11,37$ & 12,62 & 0,85 \\
\hline FDN & 41,28 & 42,85 & 36,86 & 38,45 & $\mathrm{~ns}$ & ns & $\mathrm{Y}=39,86$ & - & - \\
\hline FDA & 37,68 & 38,17 & 31,84 & 32,69 & $\mathrm{~ns}$ & ns & $Y=35,09$ & - & - \\
\hline Hemicelulose & 4,40 & 4,68 & 5,02 & 5,30 & ns & ns & $\mathrm{Y}=4,85$ & - & - \\
\hline
\end{tabular}

Matéria seca (MS), matéria mineral (MM), matéria orgânica (MO), proteína bruta (PB), fibra em detergente neutro (FDN), fibra em detergente ácido (FDA). ${ }^{1}$ Valor de $P$ para o teste de polinômio ortogonal, resposta linear (L) ou quadrática $(\mathrm{Q}) .{ }^{*}(\mathrm{p}<0,05)$.

Fonte: Elaboração dos autores. 
Os resultados deste estudo indicam que o bagaço de cana-de-açúcar enriquecido com torta de filtro apresenta potencial para ser utilizado como fonte de nutrientes para o desenvolvimento de plantas de mandioca, visto que a adição de $10 \%$ proporcionou melhorias no desenvolvimento e valor químico-bromatológica das plantas testadas. A adição de 10\% bagaço de cana-de-açúcar enriquecido proporcionou incremento na BSA e PB de plantas de mandioca quando comparado aos valores médios obtidos em plantas mantidas sem adição deste resíduo, como também essas variáveis apresentaram comportamento quadrático (Tabelas 2 e 3), demonstrado assim o potencial de aplicação deste resíduo agroindustrial no cultivo de plantas de mandioca. Apesar de não ter ocorrido efeito significativo linear ou quadrático para BFR e BSR, a adição de $10 \%$ de bagaço de cana-deaçúcar enriquecido possibilitou a formação inicial de tubérculos no período de 90 dias de cultivo, melhorando assim o desenvolvimento radicular destas plantas.

Resultados similares utilizando outras fontes de resíduo vegetal foram obtidos por Amabile et al. (1994) com restos de cultura de C. juncea na produção de BFR de plantas de mandioca e Otsubo et al. (2008) aplicando resíduos de P. glaucum. Okon et al. (2010) demonstraram ainda que maior peso fresco dos tubérculos em plantas de mandioca pode ser obtido com a adição de resíduo orgânico e inoculação com $G$. deserticola, verificando assim, o sinergismo da adubação orgânica juntamente com a inoculação micorrízica em incrementar a produtividade de plantas de mandioca.

Não houve efeito significativo da adição de bagaço de cana de açúcar enriquecido na CM e NG em plantas de mandioca (Tabela 2). Numericamente houve favorecimento da esporulação dos FMA autóctones a partir da adição de $5 \%$ de bagaço de cana-de-açúcar enriquecido, enquanto a dose a partir de $10 \%$ resultou em redução da CM. Os trabalhos de Okon et al. (2010) e Schiavo et al. (2010) demonstram aumento na colonização micorrízica em solo suplementado com 5 ton/ha de resíduo de Gliricidia sepim L. e Senna siameae Lam. e 120 ton/ha de composto orgânico (Organosuper $($ ), respectivamente, enquanto que Silva et al. (2006) e Tristão, Andrade e Silveira (2006) constataram redução significativa da colonização radicular nas plantas cultivadas em solos com adição de resíduo orgânico e afirmam que a dose e fonte de resíduo aplicada, além do tipo de solo, podem ser os responsáveis por essa redução.

Mesmo sabendo que o número de glomerosporos possa ser reduzido pela adição de $\mathrm{MO}$ ao solo, a exemplo do ocorrido quando se aplicou lodo de curtume por Nakatani et al. (2011), o bagaço de cana-de-açúcar enriquecido não influenciou a esporulação dos FMA autóctones. Tal fato sugere que a composição química do solo não foi alterada drasticamente, como ocorre com a adição de lodo de curtume, com aumento nos teores de chumbo (9,3 $\mathrm{mg} / \mathrm{kg})$, cromo (580 mg/kg) e níquel (7,3 mg/kg), ou que a comunidade autóctone pode apresentar maior tolerância às mudanças que podem ser provocadas pela adição deste tipo de resíduo.

Verificou-se ainda que plantas de mandioca cultivadas com $15 \%$ bagaço de cana-de-açúcar enriquecido apresentavam maior valor médio para MM na parte aérea em relação às cultivadas sem de adição do resíduo (Tabela 3). Os benefícios advindos da adição de outras fontes de MO neste parâmetro foi demonstrado por Vasconcelos et al. (2010).

A adição de resíduo a partir de 5\% reduziu os teores de $\mathrm{MO}$, resultando em comportamento quadrático, enquanto para o teor de $\mathrm{PB}$, houve incremento com adição de bagaço de cana-deaçúcar enriquecido até a dose de $10 \%$ de resíduo (Tabela 3). A aplicação de $10 \%$ de esterco bovino também promoveu aumento no teor de nitrogênio (N) de plantas de mamoeiro (TRINDADE; FARIA; ALMEIDA, 2000), reduzindo posteriormente de acordo com aumento nas doses aplicadas. Isso confirma a influência da dose aplicada sobre a promoção no teor de nutrientes. 
Visto que os solos da região semi árida, em geral, apresentam baixos teores de MO (PRIMO; MENEZES; SILVA, 2011), a utilização de bagaço de cana-de-açúcar enriquecido com torta de filtro pode ser alternativa para suprir esta carência e reduzir o impacto ambiental que pode ser gerado com o descarte deste tipo de resíduo. Desta forma, sugere-se a utilização do bagaço de canade-açúcar enriquecido com torta de filtro para o desenvolvimento de plantas de mandioca na região semiárida.

\section{Conclusão}

A adição de $10 \%$ de resíduo de bagaço de canade-açúcar enriquecido melhora o desenvolvimento inicial, a matéria mineral e o teor de proteína bruta, sem alterar a associação micorrízica de plantas de mandioca variedade 'Engana ladrão', podendo ser alternativa de matéria orgânica para aumentar o valor nutritivo da forragem.

\section{Agradecimentos}

À FACEPE pela concessão de bolsa de mestrado (J.M.L. Nascimento) e apoio financeiro (APQ 1265-2.03/10), ao CNPq pela bolsa PQ (A.M. YanoMelo) e auxílio financeiro (Proc. 562637/2010-9 e Proc. 559248/2009-1), à Univasf pelo uso das instalações e à Embrapa Semiárido (Alineaurea Florentino Silva) pelo auxílio no desenvolvimento dos trabalhos.

\section{Referências}

AMABILE, R. F.; CORREIA, J. R.; FREITAS, P. L. de; BLANCANEAUX, P.; GAMALIEL, J. Efeito do manejo de adubos verdes na produção de mandioca (Manihot esculenta CRANTZ). Pesquisa Agropecuária Brasileira, Brasília, v. 29, n. 8, p. 1193-1199, 1994.

BALOTA, E. L.; LOPES, E. S.; HUNGRIA, M.; DOBEREINER, J. Inoculação de bactérias diazotróficas e fungos micorrízicos arbusculares na cultura da mandioca. Pesquisa Agropecuária Brasileira, Brasília, v. 32, n. 6, p. 627-639, 1997.
BELTRÃO, F. A. S.; PIMENTA FILHO, E. C.; PAES, R. A.; SOLTO, J. S.; MADALENA, J. A. S. Comportamento da maniçoba (Manihot pseudoglaziovii Muell. Arg.) sob diferentes espaçamentos e adubações. Caatinga, Mossoró, v. 21, n. 4, p. 163-166, 2008.

BURGOS, A. M.; AVANZA, M. M.; BALBI, C. N.; PRAUSE, J.; ARGUELlO, J. A. Modelos para La estimación no destructiva del área foliar de dos cultivares de mandioca (Manihot esculenta Crantz.) em La Argentina. Agriscientia, Córdoba, v. 27, n. 1, p. 55-61, 2010.

CALGARO, H. F.; VALÉRIO FILHO, W. V. V.; AQUINO, S. S.; MALTONI, K. L.; CASSIOLATO, A. M. R. Adubação química e orgânica na recuperação fertilidade de subsolo degradação e na micorrização do Stryphnodendron polyphyllum. Revista Brasileira de Ciência do Solo, Viçosa, v. 32, n. 3, p. 1337-1347, 2008.

COLOZZI-FILHO, A.; NOGUEIRA, M. A. Micorrizas arbusculares em plantas tropicais: café, mandioca e cana-de-açúcar. In: SILVEIRA, A. P. D.; FREITAS, S. S. Microbiota do solo e qualidade ambiental. Campinas: Instituto Agronômico, 2007. p. 39-56.

DEVIDE, A. C. P.; RIBEIRO, R. L. D.; VALLE, T. L.; ALMEIDA, D. L.; CASTRO, C. M.; FELTRAN, J. C. Produtividade de raízes de mandioca consorciada com milho e caupí em sistema orgânico. Bragantia, Campinas, v. 68, n. 1, p. 145-153, 2009.

FERREIRA, A. L.; SILVA, A. F.; PEREIRA, L. G. R.; BRAGA, L. G. T.; MORAES, S. A.; ARAUJO, G. G. L. Produção e valor nutritivo da parte aérea da mandioca, maniçoba e pornunça. Revista Brasileira de Saúde e Produção Animal, Salvador, v. 10, n. 1, p. 129-136, 2009.

FERREIRA, L. E.; ANDRADE, L. A. de; GONÇALVES, G. S.; SOUZA, E. P. de; FERREIRA H. V. Diâmetro de estacas e substratos na propagação vegetativa de maniçoba, Manihhot glaziovii Muell. Arg. Revista Ciência Agronômica, Fortaleza, v. 41, n. 3, p. 393-402, 2010.

GERDEMANN, J. W.; NICOLSON, T. H. Spores of mycorrhizal Endogone species extracted from soil by wet sieving and decanting. Transactions of the British Mycological Society, Londres, v. 46, n. 2, p. 235-244, 1963.

GIOVANETTI, M.; MOSSE, B. An evaluation of techniques for measuring vesicular-arbuscular mycorrhizal infection in roots. New Phytologist, Cambridge, v. 84, n. 3, p. 489-500, 1980.

JENKINS, W. R. A rapid centrifugal-flotation technique for separating nematodes from soil. Plant Disease Report, Saint Paul, v. 48, n. 4, p. 692, 1964. 
MIRANDA, J. M.; RIGONE, M. V.; SILVEIRA, F. T. Associação da Crotalária com adubação orgânica e mineral na produtividade da cana-de-açúcar. Bioscience Journal, Uberlândia, v. 27, n. 6, p. 948-953, 2011.

NAKATANI, A. S.; MESCOLOTTI, D. L. C.; NOGUEIRA, M. A.; MARTINES, A. M.; MIYAUCHI, M. Y. H.; STURMER, S. L.; CARDOSO, E. J. B. N. Dosage-dependent shift in the spore community of arbuscular mycorrhizal fungi following application of tannery sludge. Mycorrhiza, Heidelberg, v. 21, n. 6, p. 515-522, 2011.

NASSAR, N. M. A; ORTIZ, R. Cassava improvement: challences and impacts. Journal of Agricultural Science, Cambridge, v. 145, n. 2, p. 163-171, 2006.

PHILLIPS, J. M.; HAYMAN, D. S. Improved procedures for clearing roots and staining parasitic and vesiculararbuscular mycorrhizal fungi for rapid assessment of infection. Transactions of the British Mycological Society, Londres, v. 55, n. 1, p. 158-161, 1970.

OMORUSI, V. I.; AYANRU, D. K. G. Effect of NPK fertilizer on diseases, pests and mycorrhizal symbiosis in cassava. International Journal of Agriculture and Biology, Pakistan, v. 13, n. 3, p. 391-395, 2011.

OKON, I. E.; SOLRGES, C.; OMON, M. G.; OSONUBI, O. The effects of arbuscular mycorrhizal fungal inoculation and mulch of contrasting chemical composition on the yield of cassava under humid tropical conditions. The Scientific World Journal, New York, v. 10, p. 505-511, 2010.

OTSUBO, A. A.; MERCANTE, F. M.; SILVA, R. F.; BORGES, C. D. Sistemas de preparo do solo, plantas de cobertura e produtividade da cultura da mandioca. Pesquisa Agropecuária Brasileira, Brasília, v. 43, n. 3, p. 327-332, 2008.

PRIMO, D. C.; MENEZES, R. S. C.; SILVA, T. O. Substâncias húmicas da matéria orgânica do solo: uma revisão de técnicas analíticas e estudos no nordeste brasileiro. Scientia Plena, Aracaju, v. 7, n. 11, p. 1-13, 2011.
SCHIAVO, J. A.; SILVA, C. A.; ROSSET, J. S.; SECRETTI, M. L.; SOUZA, R. A. C.; CAPPI, N. Composto orgânico e inoculação micorrízica na produção de mudas de pinhão manso. Pesquisa Agropecuária Tropical, Goiás, v. 40, n. 3, p. 322-329, 2010.

SILVA, D. J.; QUEIROZ, A. C. Análise de alimentos: métodos químicos e biológicos. 3. ed. Viçosa: UFV, 2002. 235 p.

SILVA, M. A.; SILVA, F. S. B.; YANO-MELO, A. M.; MELO, N. F.; MAIA, L. C. Fungos micorrízicos arbusculares e vermicomposto na aclimatação de Alpinia purpurata (Viell.) Schum e Zingiber spectabile Griff. (Zingiberaceae). Acta Botanica Brasilica, São Paulo, v. 20, n. 2, p. 249-256, 2006.

SILVA, R. L. N. V.; ARAÚJO, G. G. L.; SOCORRO, E. P.; OLIVEIRA, R. L.; GARCEZ NETO, A. F.; BAGALDO, A. R. Níveis de farelo de melancia forrageira em dietas para ovinos. Revista Brasileira de Zootecnia, Viçosa, MG, v. 38, n. 6, p. 1142-1148, 2009.

SMITH, S. E.; READ, D. J. The symbionts forming arbuscular mycorrhizas. In: Mycorrhizal symbiosis. 3. ed. London: Academic Press, 2008. p. 1341 .

TRINDADE, A. V.; FARIA, N. G.; ALMEIDA, F. P. Uso de esterco no desenvolvimento de mudas de mamoeiro colonizadas com fungos micorrízicos. Pesquisa Agropecuária Brasileira, Brasília, v. 35, n. 7, p. 13891394, 2000.

TRISTÃO, F. S. M.; ANDRADE, S. A. L.; SILVEIRA, A. P. D. Fungos micorrízicos arbusculares na formação de mudas de cafeeiro, em substratos orgânicos comerciais. Bragantia, Campinas, v. 65, n. 4, p. 649-658, 2006.

VALE, F. X. R.; FERNANDES FILHO, E. I.; LIBERATO, J. R. QUANT. A software plant disease severity assessment. In: INTERNATIONAL CONGRESS OF PLANT PATHOLOGY, 8., 2003, Christchurch New Zealand. Proceedings... Christchurch New Zealand: [s.n], 2003. p. 105.

VASCONCELOS, W. A. de; SANTOS, E. M.; EDVAN, R. L.; SILVA, T. C. da; MEDEIROS, G. R. de; SOUTO FILHO, L. T. Morfometria, produção e composição bromatológica da maniçoba e pornuncia, em diferentes fontes de adubação. Revista Trópica - Ciências Agrárias e Biológicas, Chapadinha, v. 4, n. 2, p. 37, 2010. 